\title{
Research and development in the NHS
}

\author{
New lamps for old
}

ALISTAIR BURNS and SHÔN LEWIS

Research in National Health Service (NHS) facilities has been undertaken since the creation of the service and significant changes in the way research is funded are taking place. The purpose of this article is to summarise the current situation.

Traditionally, the extra cost of teaching hospitals was covered by SIFTR (Service Increment for Teaching and Research), weighted in a ratio of $3: 1$ in favour of teaching. As the number of medical students was fairly easily ascertainable, this decided how much money went to the teaching hospitals, and the research portion of SIFTR followed inevitably to the same institutions. In 1988, the House of Lords Select Committee in Science and Technology published a report in Medical Research noting that ". . . the NHS should articulate its need (for research); it should assist meeting those needs and it should ensure that the fruits of research are systematically transferred into service" (quoted in Department of Health, 1991).

Part of the Government's response was to create a new post of Director of Research and Development, held by Professor Sir Michael Peckham, and recently succeeded by Professor John Swales. A document was published in 1991 (Department of Health, 1991), a task force set up under the chairmanship of Professor Anthony Culyer (Professor of Economics at the University of York) and the report of the task force published three years later (Department of Health, 1994).

The principles governing research and development as funded by the NHS were made explicit. The work should be designed to provide new knowledge; be designed so that the findings could be generalised; follow a defined protocol; involve peer review; have local research ethical committee approval; have defined arrangements for project management and have plans for dissemination, normally involving publication. The emphasis was along the main themes of transparency, accountability and equity of access to research and development funds. It was recommended that the trust subsidy between patient care and research and development should cease. There should be concentration on outcomes and performance and, most importantly, the allocation of funding should be done on a competitive basis. Thus, the traditional distribution of funds to the major teaching hospitals should be challenged and every provider (anyone who provides care funded by the NHS, that is, trusts, family doctors, dentists, community health service trusts or independent-sector providers) should have the right to bid on a competitive basis for the funds available.

\section{THE CULYER DECLARATION}

The first step was to commission an exercise whereby research and development already being carried out in provider units was documented. The NHS Executive required all NHS trusts to declare, to them, by 31 March 1996, their net costs of carrying out and supporting non-commercial research and development (it was assumed that commercially sponsored research, mostly drug trials, was fully funded with no subsidy from NHS funds). Known as the 'Culyer Return' or 'Culyer Declaration', the total declared for England was $£ 334000000$, representing some 39000 projects. This was $£ 4000000$ short of the estimated sum being currently provided, which meant that research monies were subsidising the patient care deficit. Individual regional totals are shown in Table 1.

Under the new method of funding the initial research and development Levy will be something over $£ 400000000$ : the sum of the costs declared by trusts plus the amount the NHS Executive retains for national and regional programmes (see Fig. 1).

\section{THE NEW BIDDING PROCESS}

For the first time the funding system will distribute money in two schemes, 'portfolio funding' and 'task linked funding'. There is no new money for research projects, the money already exists in the contracts provided to trusts.

Portfolio funding is aimed at NHS providers whose research and development costs are predictable in four-year blocks (three years in the first instance) and are intended to cover the costs of all research and development activity. It is open to all NHS providers who have a demonstrable ability to manage a portfolio of funds (rather than individual projects and programmes) as part of a research and development strategy. They will be subject to only periodic review by the NHS Executive and a single contract in a single block of funds for all research and development activity will be provided. The advantage of portfolio funding is that there is security over the period of funding, that individual projects and plans are decided at a local level and that responsibility is held locally rather than centrally.

Task linked funding is directed at providers for whom portfolio funding is not appropriate, that is those who are ineligible or unwilling to bid for portfolio funds or, in practice, those without existing research and development funds. Applications are made annually for particular activities and/or resources.

Providers can bid either alone or together in a consortium, which can take several forms: a grouping of similar providers, or a trust in a group with local general practitioners, for instance. Bidders for portfolio funding cannot be a member of

Table I Net cost of non-commercial research and development by NHS region at 31 March 1996.

\begin{tabular}{lc}
\hline Region & $\begin{array}{c}\text { Net cost of non- } \\
\text { commercial research } \\
\text { and development }\end{array}$ \\
\hline Anglia \& Oxford & 17 \\
North Thames & 190 \\
North West & 19.5 \\
North Yorkshire & 15.5 \\
South Thames & 48.5 \\
South West & 50 \\
Trent & 19.5 \\
West Midlands & 9 \\
\hline
\end{tabular}




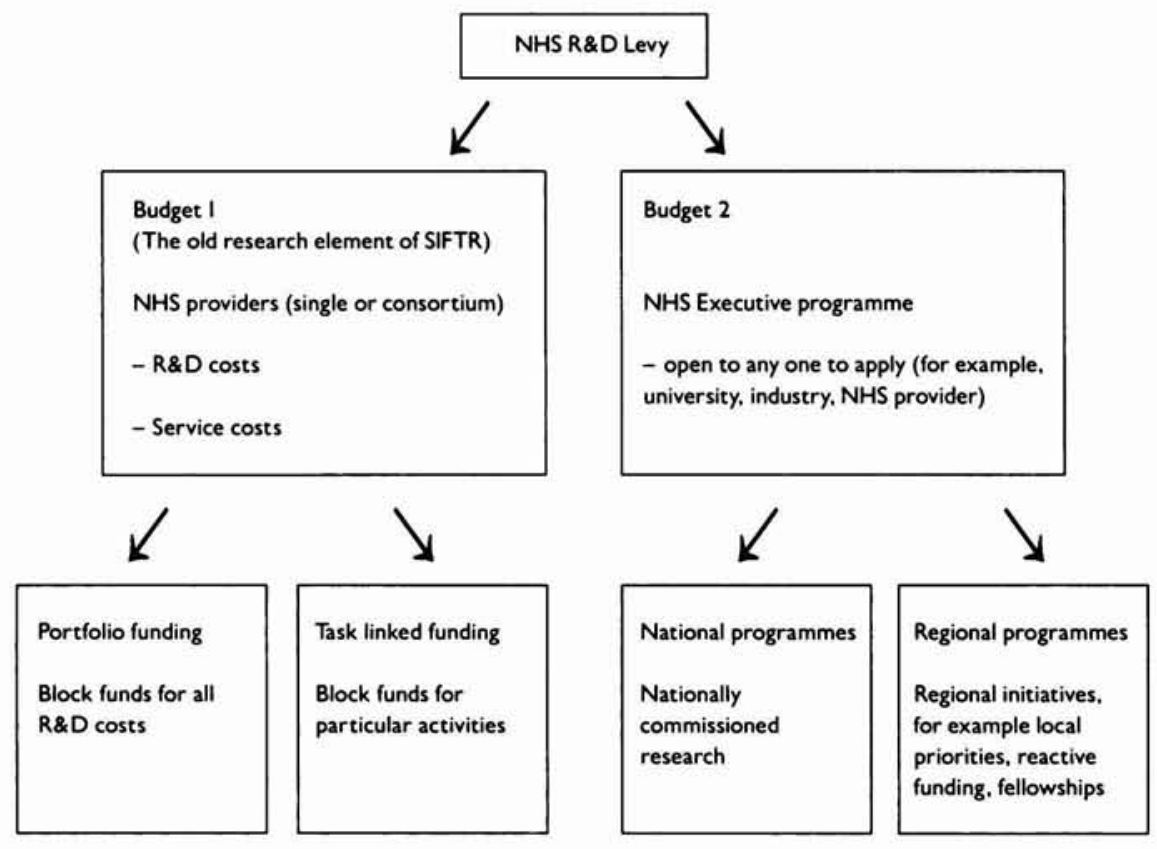

Fig. I The new research and development funding system.

more than one consortium (because the entirety of the estimated costs of research and development need to come through a single contract) but applicants for task linked funding can be a member of one or more consortia. Universities are ineligible to apply for research and development funding. However, it is made clear in the strategic framework (the partnership dimension) that local purchasers and universities should be involved in discussions.

\section{THE STRATEGIC FRAMEWORK}

The strategic framework (Department of Health, 1997) describes the purpose of the research and development levy and sets out the 10 principles (dimensions) that govern the allocation of funds. These are:

I. Quality. Appropriate prevailing professional standards will be those by which work will be judged as being of good quality. This means it will be expected that all recipients of money will have to demonstrate high levels of quality, and monitoring systems will be required to improve and sustain the quality of research.

2. Ethics. Funds will only be given for work which has attained, where necessary, local ethics committee approval.

3. Relevant impact and importance. Monies will only be used to support research which is relevant to health care and which will contribute to evidence-based practice within the NHS. This will make providers ensure that research activity is relevant to NHS needs. The NHS Executive would also look for research that is able to influence policy and practice with evidence that this is implemented using measures such as clinical effectiveness.

4. Primary care. Links with primary care are strongly encouraged as the belief is that research and development activity in primary care is underdeveloped. The NHS Executive is seeking the opportunity to promote the development of good quality research and development in primary care.

5. Partnership. It is important to demonstrate partnership with universities, purchasers, service users, carers, local authorities and industry.

6. Support for non-commercially externally funded research and development. The first call on the research and development levy will be to honour the NHS's undertaking to support externally funded research and development, such as projects funded by the Medical Research Council and other non-commercial bodies.

7. Appropriate disciplinary mix. The levy should only be used to support activity by people or teams with the relevant skills, and the NHS Executive will specifically promote multi-disciplinary research.
8. Cost. It is stated that funds should be used as efficiently as possible.

9. Integration with other NHS activities. It is recognised that research and development is only one of many NHS activities and that use of the levy should be integrated with, and not be disruptive of, the development of the NHS as a whole. Other aspects of the service such as patient care, professional training and education will also be considered.

10. Management. Allocations from the levy will only be made where there is evidence of effective management.

\section{NHS SUPPORT FOR NON-COMMERCIALLY EXTERNALLY FUNDED RESEARCH AND DEVELOPMENT}

This concerns money which the NHS is obliged to provide and which has first call on the research and development funds. It is the amount of NHS funding given to support research which is externally funded, excluding commercially sponsored research, the full costs of which are expected to be recovered from the commercial organisation.

These NHS costs are broken down into three categories (see Fig. 2):

(a) Research costs are those involved in carrying out the project.

(b) Service support costs are costs to the service which occur only because the research and development is taking place.

(c) Treatment costs are divided into two: first, those of a standard service (the costs to the NHS of the formal clinical service); second, extra costs which would be involved if the new treatment is greater than the existing service (excess treatment costs).

For example, the following are the costs involved in a study assessing the effectiveness of cognitive-behavioural therapy delivered by a community psychiatric nurse (CPN) for people with schizophrenia. The additional therapist time involved means that the case load of a CPN becomes 20 people instead of the usual 30 .

(a) Research costs of the project would cover the employment of staff to make ratings of patients and their relatives, economic aspects of the project and data analysis. These are costs which are clearly extra to any current or future 
service and are strictly attributable to the research process.

(b) Service support costs include extra attendance at the day hospital for the patients in the trial for the treatment to be carried out.

(c) Treatment costs include the cost of care itself (one CPN per 30 people) and, in this case, the excess treatment costs are those costs additional to the standard service lone half-time equivalent CPN to manage the reduced case load). These excess treatment costs are the costs the NHS would be expected to continue to fund if the new treatment were shown to be effective and if the cost were greater than existing costs. They may consist of staff time or, because of particular expertise, monitoring and supervision, the need for the new service to be in a particular hospital (for example, a teaching hospital) where the costs would be higher than elsewhere. It is still unclear as to how these extra treatment costs should be borne, whether they should come from local purchasers or from a central fund to be bid from at the same time as the levy. In either situation, the money comes from purchasers. The two models differ in the degree of local involvement in directing research and development.

\section{IMPLICATIONS FOR PSYCHIATRY}

To the extent that psychiatric practice is already multi-disciplinary and has a strong focus on the community and primary care.
ALISTAIR BURNS, FRCPsych, SHÖN LEWIS. FRCPsych, Withington Hospital. Manchester

Correspondence: Professor A, Burns. Director of Research and Development. Department of Psychiatry. University of Manchester. Withington Hospital, West Didsbury. Manchester M20 8LR

(First received 8 january 1997, finat revision 28 July 1997, accepted 4 September 1997) much of what is suggested in terms of the new funding arrangements falls well within the remit of our discipline. Also, mental health is a Health of the Nation priority (Department of Health, 1992) and developing community services for vulnerable people is one of the key objectives for the NHS Executive. The experience of psychiatry in terms of service evaluation and outcomes (including quality of life) means that psychiatry and clinical psychology represent a common thread for research in a number of areas. Those involved in NHS research need to be prepared to justify their research and to ensure that it satisfies the basic criteria of being of high quality and being responsive to the needs of the NHS.

\section{TIMETABLE}

The Strategic Framework was published in January 1997 with Expressions of Interest submitted to Regional Offices of the NHS Executive by the end of March 1997. Full bids were received by 30 June 1997 with provisional allocations of funding made by October 1997 when a parliamentary vote decided how much is to be spent on the NHS. Contracts for the new funding scheme start in April 1998.

\begin{tabular}{|c|c|}
\hline A - R \& D costs & B - Service support costs \\
\hline C - Standard service costs & $D$ - Excess element of treatment costs \\
& \\
\hline
\end{tabular}

Fig. 2 National Health Service (NHS) support for externally funded research. Research and development (R\&D) costs comprise the costs of data collection, analysis and staff involved in research. Service support costs comprise costs to the service which would cease if the R\&D was not taking place (e.g. additional out-patient visits. additional tests). Standard service costs comprise the costs which would be incurred by the NHS if the service was being provided outside the context of research (on the assumption that. if proven a success. the new service would be implemented). Excess element of treatment costs comprise the costs involved if the alternative service is more expensive than the existing one. whether this be the actual cost or its location. $C+D=$ treatment costs. $B+C+D=$ costs of patient service. $A+B+C+D=$ total costs.

\section{CONCLUSION}

As with other developments in the NHS, changes to research funding are inevitable and come at a time when central Government funding and research in the universities is being reviewed in the Dearing report. One cannot argue with the fundamental assumption that research funded by the NHS should be directed to areas of high priority and undertaken by groups which promise high quality. For most clinicians, the changes will pass unnoticed, but for those in teaching hospitals there may be significant investment and disinvestment in and between trusts. Inevitably the changes are perceived as being uncomfortable for some. Individual optimism of the process (every threat is an opportunity) is often countered by others (every opportunity is a threar). One of the aims of Culyer was to increase research and development spending in the NHS to $1.5 \%$ of the budget, an aim which ultimately must be best for parients.

\section{ACKNOWLEDGEMENTS}

We are grateful to Professor Maggie Pearson for reading the manuscript and to the comments of an anonymous referee for encouraging an English translation

\section{REFERENCES}

Department of Health (1991) Research for Heaith. A Reseorch and Development Strutegy for the NH'S. London: Department of Heaith.

- (1992) Health of the Notion: A Strategy for Health in Englond London HMSO

- (1994) Supporting Research and Development in the NHS London: Department of Heath.

- (1995) Supporing Reseanch and Development in the NHS A Dedoration of NHS Actrity and Costs - Gudonce on Costing and Making the Decloraton London: Department of Heaith

- (1997) The Stratege Fromework. London: Department of Heath.

NHS Executive (1996) NHS Support for NonCommercally Externaliy funded Research Development. Consultotion Document ( $96 \mathrm{CCOO}$ i) London: Department of Health. 